\title{
Validation of the Kutcher Adolescent Depression Scale in a Caribbean student sample
}

\author{
Gillian A. Lowe DM (Psych), Garth E. Lipps PhD, Roger C. Gibson DM (Psych), Mia A. Jules PhD, \\ Stanley Kutcher MD
}

\section{Abstract}

Background: Research on depression among Caribbean children has been limited by a lack of valid and reliable measures. We addressed this problem by exploring the internal consistency reliability and the concurrent and discriminant validity of the Kutcher Adolescent Depression Rating Scale (KADS) among a wide cross-section of the student population attending elementary schools in Jamaica and Barbados.

Methods: Students enrolled in grade 6 in a cross-section of schools in Jamaica and Barbados were invited to participate in the study. Schools included a balance of government-funded public schools and privately funded preparatory schools. All schools that were invited to participate accepted, and all grade 6 classrooms in each school were sampled. The following instruments were administered to the students during the fall semester of 2015: KADS, Adolescent Depression Rating Scale (ADRS), major depression disorder subscale of the Revised Children's Anxiety and Depression Scale (RCADS), and state and trait anxiety visual analogue scales.

Results: In total, 759 children (376 girls [49.5\%] and 363 boys [47.8\%]; in 20 cases [2.6\%], sex was missing) with a mean age of 10.7 (standard deviation 0.66) years (median $11.0 \mathrm{yr}$ ) took part in the study. Overall, the KADS had an acceptable degree of reliability $(\alpha=0.76)$. The instrument had reasonably good concurrent validity, as evidenced by strong correlations with scores on the ADRS $(r=0.62)$ and the major depression disorder subscale of the RCADS $(r=-0.61)$. It had acceptable discriminant validity, as shown through low correlations with the state and trait anxiety visual analogue scales $(r=0.21$ and 0.18 , respectively). This pattern of results suggests that a large part (37\%) of the variance underlying the KADS assesses depression, and a smaller degree of the variance $(3 \%-4 \%)$ measures a conceptually similar but distinct concept.

Interpretation: The KADS is a reliable and valid measure for assessing depressive symptoms among Jamaican and Barbadian elementary school students. The sample may not be representative of all Caribbean children.

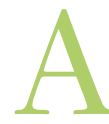
cross the world, $10 \%-20 \%$ of children and adolescents have substantial mental health problems. ${ }^{1}$ Elementary school children with depression are at greater risk for attempted and completed suicide than their healthy peers. ${ }^{2}$ Depressive disorders that occur during childhood and adolescence have documented high rates of substance abuse, teenage pregnancy and delinquency. ${ }^{3-6}$ Few investigations of depression have been performed among West Indian elementary school students, and even fewer among Jamaican and Barbadian students. ${ }^{7}$ Lowe and colleagues ${ }^{8-14}$ found that a relatively large proportion of adolescents in Caribbean secondary schools reported moderate to severe symptoms of depression, but little research has been done with preadolescents in this region.

An important prerequisite for conducting research on depression among Jamaican and Barbadian preadolescents is the availability of an instrument that is valid for this group. It is well established that cultural factors influence perceptions and interpretations and, therefore, the validity of screening tools for depression. ${ }^{15}$ The applicability of measures of depression developed elsewhere in the world must be established before any large-scale research can take place. Unique cultural factors of Jamaica and Barbados,

Competing interests: Stanley Kutcher is the creator of the Kutcher Adolescent Depression Rating Scale instruments. No other competing interests were declared.

This article has been peer reviewed.

Correspondence to: Garth Lipps, garth.lipps@uwimona.edu.jm

CMAJ Open 2018. DOI:10.9778/cmajo.20170035 
including overt academic streaming, high-stakes examinations, the implications of attending a prestigious high school for future occupational and social success, and the influence of the educational system in reproducing and maintaining a highly stratified social class system, may confer a greater risk of depression among preadolescents than in other settings. These factors make the identification of an appropriate instrument for detecting and measuring depression critical. The purpose of the current study was to assess the reliability and validity of a measure of depressive symptoms developed at Dalhousie University, Halifax, the Kutcher Adolescent Depression Scale (KADS), when used with this population. We hypothesize that the KADS will achieve concurrent, discriminant validity in a sample of Jamaican and Barbadian students and that, consistent with past literature, ${ }^{5-7}$ we there will be no sex difference in preadolescents' scores.

\section{Methods}

\section{Setting}

\section{Jamaican society}

Several social factors may place Jamaican elementary school students at elevated risk for depression. Jamaican society is strongly stratified by social class, ${ }^{16}$ which negatively affects the educational system, ${ }^{17}$ such that children of parents from lower social classes are enrolled predominantly in governmentmanaged schools, which are less well staffed and resourced than privately funded schools. ${ }^{8,13,17,18}$ Compounding this, repeated critical competency examinations, such as the Grade Six Achievement Test, in combination with high levels of poverty and unemployment and limited opportunities for social mobility may elevate the risk of depression for students. ${ }^{19}$ Given this enhanced risk, it is important to determine the characteristics and prevalence of depression among Jamaican elementary school students.

\section{Barbadian society}

Like the system in Jamaica, the Barbadian education system requires all students to sit a secondary school entrance examination (Common Entrance Examination) at 11 years of age. Students are then streamed to schools of varying quality based on their performance. The practice of streaming has arguably served to maintain the rigid stratification of social classes within the Barbadian context. ${ }^{20}$ This is primarily because working-class children tend to have inadequate parental encouragement and resources and are more likely to speak the local dialect. Hence, children of working-class parents are less likely to obtain a place at the older, more prestigious secondary schools.

\section{Consequences of high-stakes examinations}

Given the degree to which the practice of high-stakes entrance examinations is entrenched within the fabric of Jamaican and Barbadian culture and the societal pressures placed on children to succeed in examinations, the failure to achieve a place at a prestigious school can have detrimental psychological consequences for children. ${ }^{21}$ Some parents have described their child's experience of the Grade Six Achievement Test and the Common Entrance Examination as traumatic, and many children who have taken these examinations have been labelled as successes or failures by their performance; in the case of the latter, this has undermined their selfesteem. ${ }^{17,22}$ Perceived failure can also result in "alienation from parents, family and past school friends," 23 all of which can increase the predisposition for depression among this demographic group.

\section{Study design}

The overall project was a 4-group, 2-pretest, 1-posttest quasiexperiment. In the current study, we used data only from the first observation period, as it included measures to validate the KADS.

\section{Participants}

Students attending a cross-section of elementary schools in Barbados and in the Kingston and St. Andrews areas of Jamaica were assessed to obtain preliminary evidence for the validity of the KADS. Schools were chosen such that they included a balance of government-funded public schools and privately funded preparatory schools in both Jamaica and Barbados. We tried to ensure that the schools were roughly proportional in enrolment to those in their respective country. ${ }^{24,25}$ No schools that were invited to participate declined. All grade 6 classrooms in each school were sampled.

In both Jamaica and Barbados, the sixth grade is the final grade in elementary school. High schools in both countries include grades 7-11, with some schools offering an extended 2-year program (grades 12 and 13, similar to the Ontario Academic Credit), which is considered to be the equivalent of the first year of college.

\section{Measures}

\section{Kutcher Adolescent Depression Scale}

The KADS is an 11-item measure specifically designed to assess the cognitive, behavioural, affective and somatic symptoms of depression by self-report among students 12-17 years of age. ${ }^{26}$ It was developed to assess the core symptoms of adolescent depression using Standard English and the phraseology often used by adolescents. The scale has been standardized, and evidence of its validity has been obtained for depressive symptoms in several North American and Middle Eastern countries. ${ }^{27,28}$ Subjects record their responses to each item using a series of Guttman rankordered statements. The statements are assigned a score of 0-3 depending on the severity of the symptom they describe. Subjects are asked to circle the number associated with the statement that most accurately describes their feelings. Depression scores are calculated by summing the numbers associated with the circled statements. Within our sample, the KADS appeared to have a reasonable degree of internal 
consistency reliability $(\alpha=0.76)$. Past research suggested that the KADS has adequate concurrent validity, as indicated by a correlation of 0.69 with the Children's Depression Rating Scale. ${ }^{26}$

\section{Adolescent Depression Rating Scale}

The Adolescent Depression Rating Scale (ADRS) is a 10-item measure of depressive symptoms for use with adolescents. ${ }^{29}$ Subjects are asked to indicate whether each item is true or false for them. The ADRS has been found to have acceptable levels of internal consistency reliability ( $\alpha=0.74-0.79)$ as well as good concurrent validity, as shown by large correlations with the Hamilton Depression Rating Scale (0.56), ${ }^{30}$ the Beck Depression Inventory-II (0.82) ${ }^{31}$ and the Clinical Global Impression - Severity Scale (0.52). ${ }^{32}$ Within our sample, the ADRS had borderline internal consistency reliability $(\alpha=$ $0.58)$.

\section{Revised Children's Anxiety and Depression Scale}

The Revised Children's Anxiety and Depression Scale (RCADS) is a 47-item measure that assesses symptoms of anxiety and major depressive disorder. The 10-item major depression disorder subscale has an internal consistency reliability of 0.80 for clinical samples and 0.79 for school-based samples of children 6-18 years of age. ${ }^{33}$ Within our sample, the major depression disorder subscale was found to have an acceptable level of internal consistency reliability $(\alpha=0.71)$. Past research showed that the RCADS was able to successfully distinguish students with a diagnosis of an affective disorder from those without. ${ }^{33}$

\section{Visual analogue scale - anxiety}

We measured anxiety using a 100-mm horizontal line with the 2 end points labelled "no anxiety or fear" and "worst possible anxiety or fear." 34 Participants indicated their level of anxiety by marking a spot on the horizontal line. The measure correlated 0.62-0.69 with established measures of anxiety (State-Trait Anxiety Scale - Children, State-Trait Anxiety Scale - Youth and Yale Preoperative Anxiety Scale), which suggests that it has adequate concurrent validity. ${ }^{34}$ Participants were asked to rate their current level of anxiety (state anxiety) and their level of anxiety during the previous 6 months (trait anxiety).

\section{Rationale}

We included both the ADRS and the major depression disorder subscale of the RCADS in this study as both are commonly used measures of preadolescent and adolescent depressive symptoms, they are brief measures but also have strong psychometric properties (reliability and concurrent validity), and they are accepted in their field. The major depression disorder subscale was intended to be the gold-standard/reference measure, and the ADRS was included as an additional measure of validity. In validating a measure it is always important to include at least 2 different measures of the construct being validated, because if only 1 measure is included, indeterminate findings can occur. This is because a weak relation with 1 ref- erence measure may simply indicate that the 2 measures assess different facets of the same construct and not that they validly assess same construct. ${ }^{35}$

\section{Procedure}

During the fall semester of 2015, research assistants provided a brief introduction to the project at the start of the participants' regular class. The project was described as an investigation into the psychosocial factors associated with mood and social relationships. Participants were informed that their participation was completely voluntary and they could withdraw from the project at any time. Questionnaires were then distributed, with 45 minutes allowed for completion. Completed questionnaires were returned to one of the investigators at the end of the class.

\section{Definitions}

For the purposes of this study, we defined psychometric reliability as the stability of responses within the same testing session, as assessed by the Cronbach coefficient $\alpha .{ }^{36}$ Concurrent validity for the purposes of this study was operationalized by a large correlation of the KADS with the ADRS and the major depression disorder subscale of the RCADS. Discriminant validity is the degree to which a measure does not correlate with a measure of a similar but conceptually distinct construct. ${ }^{35}$ Discriminant validity was operationalized by a low correlation with the anxiety visual analogue scale. Although there are standards for interpreting and evaluating psychometric reliability, there are no standards for judging the concurrent or discriminant validity of a measure. Instead, concurrent and discriminant validity are evaluated based on the pattern of correlations between measures. In this study, for concurrent validity, there should be moderate correlation of the KADS with both the ADRS and the major depression disorder subscale of the RCADS, and low correlation of the KADS with the anxiety visual analogue scale.

\section{Statistical analysis}

We entered the data obtained from the questionnaires into SPSS version 11.5 (IBM) and analyzed them using the Pearson product-moment correlation, interitem reliability statistics, $t$ tests and principal components analysis. We used a 2-stage approach to establish the reliability and validity of the KADS. First, we examined the internal consistency reliability of the instrument using the Cronbach coefficient $\alpha .{ }^{36}$ We did so because the KADS was developed to assess change in depressive symptoms. As such, an estimate of internal consistency reliability is a better estimation of the reliability of scores than a test-retest reliability coefficient. We then examined the concurrent and discriminant validity of the KADS using the Pearson product-moment correlation. We used this statistic to estimate concurrent and discriminant validity because it assesses the extent to which scores on the KADS will covary with scores on the ADRS, the major depression disorder subscale of the RCADS and the anxiety visual analogue scale. We used the established guidelines set by Anastasi and Urbina ${ }^{37}$ and Nunally ${ }^{38}$ to 
evaluate the reliability of the study measures. Following these guidelines, a reliability coefficient of 0.60 or greater indicates an acceptable degree of reliability, a coefficient of 0.61-0.79 indicates moderate reliability, and a coefficient of 0.80 or greater indicates good reliability. ${ }^{37}$ There are no established guidelines for the judgment of validity. We evaluated validity in terms of the amount of variability shared between 2 measures of the same construct. To examine the dimensionality of the KADS, we conducted a principal components analysis of the items on the KADS using varimax rotation of components. We did so because this procedure examines the total variability rather than the common variance among the items. Before conducting all analyses, we substituted the mean score, rounded to the nearest whole number, for missing values on individual KADS items, and ADRS, major depression disorder subscale of the RCADS, and items on the state and trait anxiety visual analogue scales. We used several criteria to determine the number of components to keep (eigenvalues $>1$, scree plot, total variability accounted for by the solution, simple structure and psychological meaningfulness). ${ }^{39}$

\section{Ethics approval}

This study was approved by the ethics committees of the Mona and Cave Hill campuses of The University of the West Indies. All parents and children were asked to provide their written informed consent and assent before collection of data.

\section{Results}

In Jamaica, all students who were present on the day of data collection were included in the sample. In Barbados, only $38 \%$ of the students whose parents consented took part in the study, as some children did not complete the informed assent form or were not present on the day of data collection. In total, 759 children (376 girls [49.5\%] and 363 boys [ $47.8 \%$ ]; in 20 cases [2.6\%], sex was missing) aged 9-12 years (mean $10.7 \mathrm{yr}$ [standard deviation (SD) $0.66 \mathrm{yr}$ ], median $11.0 \mathrm{yr}$ ) took part in the study (Figure 1). The distribution of students in our sample by grade and sex closely represented that for the government schools (Table 1). However, there were slightly more male students (48.7\% v. $46.4 \%)$ and slightly fewer female students $(51.3 \%$ v. $53.6 \%)$ in private schools in our sample than in the general population.

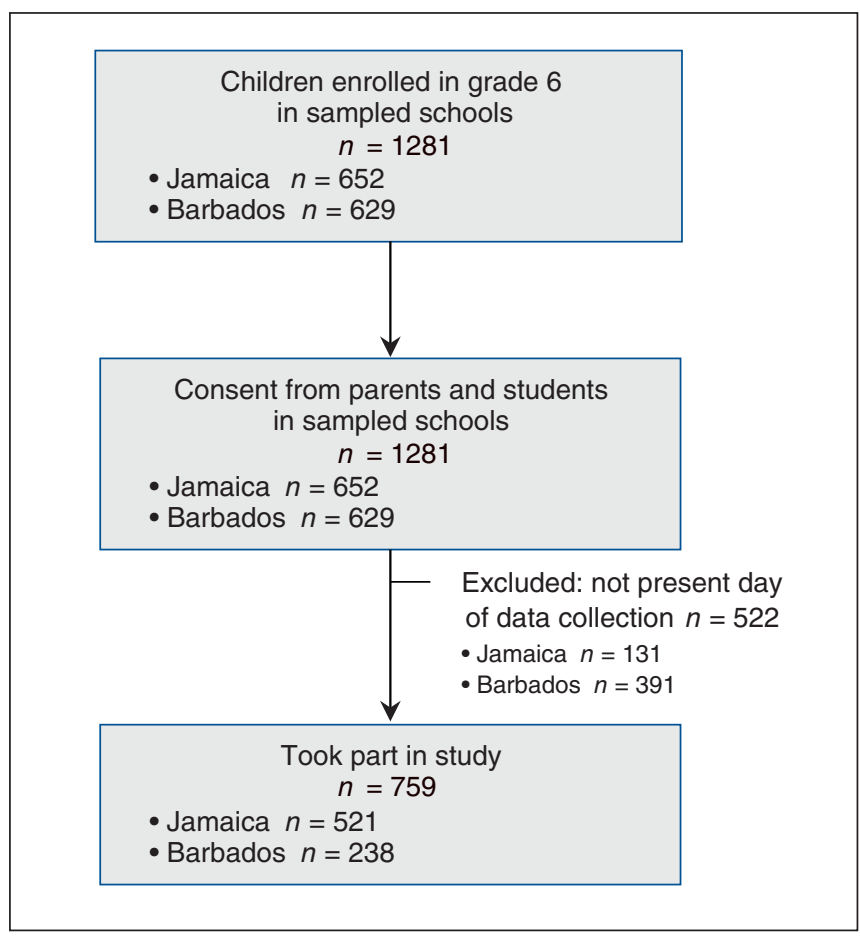

Figure 1: Flow diagram showing participant selection.

\begin{tabular}{|c|c|c|c|c|}
\hline \multirow[b]{2}{*}{ Characteristic } & \multicolumn{2}{|c|}{ Sample, no. (\%) of children } & \multicolumn{2}{|c|}{$\begin{array}{l}\text { Jamaica and Barbados, } \\
\text { no. }(\%) \text { of children }{ }^{24,25}\end{array}$} \\
\hline & $\begin{array}{l}\text { Government-funded } \\
\text { schools } \\
n=605\end{array}$ & $\begin{array}{l}\text { Privately funded } \\
\text { schools } \\
n=154\end{array}$ & $\begin{array}{c}\text { Government- } \\
\text { funded schools } \\
n=8881\end{array}$ & $\begin{array}{c}\text { Privately funded } \\
\text { schools } \\
n=1248\end{array}$ \\
\hline \multicolumn{5}{|l|}{ Sex } \\
\hline Male & $288(47.6)$ & $75(48.7)$ & $4447(50.1)$ & $579(46.4)$ \\
\hline Female & $297(49.1)$ & 79 (51.3) & $4434(49.9)$ & $669(53.6)$ \\
\hline Missing & $20(3.3)$ & $0(0)$ & - & - \\
\hline \multicolumn{5}{|l|}{ Maternal education } \\
\hline Primary or less & $66(11.3)$ & $4(2.6)$ & - & - \\
\hline High school & $205(35.0)$ & $16(10.4)$ & - & - \\
\hline Trade/vocational & $62(10.6)$ & $15(9.7)$ & - & - \\
\hline University/college & $190(32.5)$ & $102(66.2)$ & - & - \\
\hline Missing & $62(10.6)$ & $17(11.0)$ & - & - \\
\hline Age, yr, mode & 11 & - & 11 & - \\
\hline
\end{tabular}




\begin{tabular}{|c|c|c|c|c|c|}
\hline \multirow[b]{2}{*}{ Instrument } & \multicolumn{5}{|c|}{ Instrument; coefficient } \\
\hline & KADS & $\begin{array}{c}\text { Major depression } \\
\text { disorder subscale, } \\
\text { RCADS }\end{array}$ & ADRS & $\begin{array}{c}\text { State anxiety } \\
\text { visual analogue } \\
\text { scale }\end{array}$ & $\begin{array}{c}\text { Trait anxiety } \\
\text { visual analogue } \\
\text { scale }\end{array}$ \\
\hline KADS & 1.00 & - & - & - & - \\
\hline $\begin{array}{l}\text { Major depression disorder } \\
\text { subscale, RCADS }\end{array}$ & 0.62 & 1.00 & - & - & - \\
\hline ADRS & 0.61 & 0.63 & 1.00 & - & - \\
\hline $\begin{array}{l}\text { State anxiety visual } \\
\text { analogue scale }\end{array}$ & 0.21 & 0.19 & 0.14 & 1.00 & - \\
\hline $\begin{array}{l}\text { Trait anxiety visual } \\
\text { analogue scale }\end{array}$ & 0.17 & 0.27 & 0.16 & 0.31 & 1.00 \\
\hline
\end{tabular}

Overall, results of the validity analyses suggested that the KADS has an acceptable degree of concurrent and discriminant validity (Table 2). Scores on the KADS correlated with the major depression disorder subscale of the RCADS $(r=$ $0.62)$ and with the ADRS $(r=0.61)$, which suggests that the KADS has a moderate degree of concurrent validity. In contrast, KADS scores correlated weakly with scores on the state and trait anxiety visual analogue scales $(r=0.21$ and 0.17 , respectively), which suggests that the KADS has an acceptable degree of discriminant validity. This pattern of scores suggests that a large part of the stable variance underlying the KADS assesses depression (37\%) and that a smaller degree of the variability $(3 \%-4 \%)$ measures a conceptually similar but distinct construct.

As expected, there was no significant sex difference in KADS scores. Girls had a mean score of 10.76 (SD 6.66), and boys had a mean score of 10.10 (SD 5.93).

We compared KADS scores between public and private schools. Students in public schools were found to have significantly higher KADS scores than those in private schools (11.74 [SD 6.24] v. 9.62 [SD 6.63], $p<0.001)$.

On principal components analysis of the KADS, 2 clear components emerged that accounted for $39.2 \%$ of the total variability in the participants' scores. Component 1 consisted of cognitive-somatic symptoms of depression, and component 2 consisted of affective symptoms of depression (Table 3 ).

\section{Interpretation}

We found that the KADS had an acceptable level of concurrent and discriminant validity in Jamaican and Barbadian schoolchildren aged 9-12. It also had an acceptable level of internal consistency reliability. Thus, the instrument appears to be an appropriate measure of depression among preadolescent Caribbean children. As expected, we did not find a sex difference in KADS scores.

Our findings are similar to those of validation studies conducted in Iran, ${ }^{28}$ the Philippines ${ }^{40}$ and China. ${ }^{41}$ The KADS

\begin{tabular}{|lcc|}
\hline \multirow{2}{*}{$\begin{array}{l}\text { Table 3: Rotated component matrix from a principal } \\
\text { components analysis of the Kutcher Adolescent Depression } \\
\text { Scale }\end{array}$} & \multicolumn{2}{|c|}{ Factor loading } \\
\hline & Component 1 & Component 2 \\
\hline Item & 0.707 & - \\
\hline Feelings of worthlessness & 0.620 & - \\
\hline Feeling tired & 0.568 & - \\
\hline Physical feelings of worry & 0.545 & - \\
\hline Trouble concentrating & 0.523 & - \\
\hline $\begin{array}{l}\text { Feeling worried, nervous, } \\
\text { panicky, tense }\end{array}$ & 0.453 & - \\
\hline $\begin{array}{l}\text { Feeing that life is not very } \\
\text { much fun }\end{array}$ & 0.429 & 0.823 \\
\hline \begin{tabular}{l} 
Sleep difficulties \\
\hline Feeling decreased interest
\end{tabular} & - & 0.541 \\
\hline $\begin{array}{l}\text { Low mood, sadness, feeling } \\
\text { blah, depressed, just can't be } \\
\text { bothered }\end{array}$ & - & 0.503 \\
\hline $\begin{array}{l}\text { Thoughts, plans or actions } \\
\text { about suicide or self-harm }\end{array}$ & - & \\
\hline $\begin{array}{l}\text { Irritable, losing your temper } \\
\text { easily, feeling pissed off, } \\
\text { losing it }\end{array}$ & - & \\
\hline
\end{tabular}

had comparable levels of internal consistency reliability and similar levels of concurrent validity, and consisted of 2 principal components that were similar in structure to ours.

\section{Limitations}

One limitation of the current project is the sampling of sixthgrade schoolchildren. This population is not representative of the full range of children and adolescents in Jamaica and Barbados. We plan to conduct further studies using a broader and more representative sample of the Jamaican and Barbadian 
population. Second, the KADS was designed to assess youth aged 12-17. However, in the current study, students ranged in age from 9 to 12 years. As is standard practice for dealing with missing values on specific variables in data sets where data are missing for less than $5 \%$ of all cases on a specific variable, ${ }^{39}$ the mean score for the specific variable was substituted for the missing value on that specific variable. Consequently, the variability of the study variables may have been slightly truncated, thereby underestimating reliability and validity values. Despite these limitations, the current study provides preliminary evidence for the concurrent and discriminant validity of the KADS. Our principal components analysis accounted for only $39 \%$ of the total variability among the KEDS items. Although this is more than acceptable and is often found in analysis of measures, it suggests that a substantial amount of the variability in the KADS may be random. Researchers who revise the KADS in the future may wish to reduce the random variability in the measure.

\section{Conclusion}

The KADS is a reliable and valid measure of depressive symptoms for children aged 9-12 years that may be used to screen Jamaican and Barbadian youth. We plan to examine the role that parenting practices, academic school performance, neighbourhood factors and socioeconomic status may play in levels of depression as measured with the KADS.

\section{References}

1. Kieling C, Baker-Henningham H, Belfer $M$, et al. Child and adolescent mental health worldwide: evidence for action. Lancet 2011;378:1515-25.

2. Daughtry D, Kunkel M. Experience of depression in college students: a concept map. 7 Couns Psychol 1993;40:316-23.

3. Deykin EY, Levy JC, Wells V. Adolescent depression, alcohol and drug abuse. Am 7 Public Health 1987;77:178-82.

4. Hodgkinson SC, Colantuoni E, Roberts D, et al. Depressive symptoms and birth outcomes among pregnant teenagers. 7 Pediatr Adolesc Gynecol 2010;23: 16-22.

5. Kofler MJ, McCart MR, Zajac K, et al. Depression and delinquency covariation in an accelerated longitudinal sample of adolescents. 7 Consult Clin Psychol 2011;79:458-69.

6. Rao U. Links between depression and substance abuse in adolescents. $A m \mathcal{F}$ Prev Med 2006;31(6 Suppl 1):S161-74.

7. Lambert MC, Puig M, Lyubansky M, et al. Child behavior and emotional problems in Jamaican classrooms: a multimethod study using direct observations and teacher reports for ages 6-11. Int f Intercult Relat 2001;25:545-62.

8. Lipps G, Lowe GA, Halliday S, et al. The association of academic streaming to depressive symptoms in adolescents across three Caribbean countries. Child Adolesc Ment Health 2010;4:1-10.

9. Lipps GE, Lowe GA. Validation of the brief screen for depression in a Jamaican cohort. West Indian Med 7 2006;55:425-9.

10. Lipps GE, Lowe GA, Morris A, et al. School factors associated with depression in a Jamaican high school cohort. F Black Psychol 2010;36:369-80.

11. Lipps GE, Lowe GA, Young R. Validation of the Beck Depression Inventory-II in a Jamaican university student cohort. West Indian Med 7 2007;56:404-8.

12. Lowe GA, Lipps G, Gibson R, et al. Neighbourhood factors and depression among adolescents in four Caribbean countries. PLoS One 2014;9: e95538.

13. Lowe GA, Lipps G, Halliday S, et al. Depressive symptoms among fourth form students in St. Kitts and Nevis high schools. ScientificWorldfournal 2009;9:149-57.

14. Lowe GA, Lipps GE, Young R. Factors associated with depression among students of the University of the West Indies - Mona. West Indian Med 7 2009;58:21-7.

15. Kerr LK, Kerr LD Jr. Screening tools for depression in primary care: the effects of culture, gender, and somatic symptoms on the detection of depression. West 7 Med 2001;175:349-52.

16. Miller E. Famaican society and high schooling. Kingston (Jamaica): Institute of Social and Economic Research, The University of the West Indies; 1990.

17. Evans H, editor. Streaming and its effects on students. In: Inside Famaican schools. Kingston (Jamaica): The University of the West Indies Press; 2001: 90-104.
18. Lowe GA, Lipps GE, Abel W. Depression among fourth-form students in three high schools in Kingston, Jamaica. Caribb 7 Psychol 2005;2:32-49.

19. Harriott A. The crisis of public safety in Jamaica and the prospects for change. Souls 2001;3:56-65.

20. Best T. Achieving excellence in education: John Cumberbatch Memorial Lecture. Barbados Union of Teachers Teachers Week; 2008 Oct. 29; St. Michael (Barbados).

21. Erikson EH, Erikson JM. The life cycle completed (extended version). New York: WW Norton \& Company; 1998.

22. National Advisory Commission on Education. Educating in the new century transforming education for sustainable development: a national consultation on education in Barbados. St. Michael (Barbados): Minister of Education, Human Resources and Development; 2010.

23. Maynard DM. Learned helplessness in Barbadian adolescents: psychosocial variables and learned helplessness. Saarbrücken (Germany): Lambert Academic Publishing; 2010.

24. 2013-2014 statistics on education in Barbados at a glance. Bridgetown (Barbados): Ministry of Education, Science, Technology and Innovation.

25. Education statistics, 2014-2015 - annual statistical review of the education sector. Kingston (Jamaica): Planning and Development Division, Statistics Section, Ministry of Education.

26. Brooks S. The Kutcher Adolescent Depression Scale (KADS). Child Adolesc Psychopharmacol News 2004;9:4-6.

27. Brooks SJ, Krulewicz SP, Kutcher S. The Kutcher Adolescent Depression Scale: assessment of its evaluative properties over the course of an 8-week pediatric pharmacotherapy trial. 7 Child Adolesc Psychopharmacol 2003;13:337-49.

28. Shahidi M, Shojaee M. Psychometric properties and diagnostic utility of the 11-item Kutcher Adolescent Depression Scale (KADS-11) in Persian samples. Int 7 Psychol Behav Sci 2014;4:201-7.

29. Revah-Levy A, Birmaher B, Gasquet I, et al. The Adolescent Depression Rating Scale (ADRS): a validation study. BMC Psychiatry 2007;7:2.

30. Hamilton M. A rating scale for depression. I Neurol Neurosurg Psychiatry 1960; 23:56-62.

31. Beck AT, Steer RA, Brown GK. Manual for the Beck Depression Inventory-II. San Antonio (TX): Psychological Corporation; 1996.

32. Kadouri A, Corruble E, Falissard B. The improved Clinical Global Impression Scale (iCGI): development and validation in depression. BMC Psychiatry 2007; $7: 7$.

33. Ebesutani C, Reise SP, Chorpita BF, et al. The Revised Child Anxiety and Depression Scale - short version: scale reduction via exploratory bifactor modeling of the broad anxiety factor. Psychol Assess 2012;24:833-45.

34. Aitken RCB. Measurement of feelings using visual analogue scales. Proc $R$ Soc Med 1969;62:989-93.

35. Campbell DT, Fiske DW. Convergent and discriminant validation by the multitrait-multimethod matrix. Psychol Bull 1959;56:81-105.

36. Cronbach L. Coefficient alpha and the internal structure of tests. Psychometrika 1951;16:297-334.

37. Anastasi A, Urbina S. Psychological testing. 7th ed. Upper Saddle River (NJ) Prentice Hall; 1997.

38. Nunnally JC. Psychometric theory. New York: McGraw-Hill; 1978.

39. Tabachnick BG, Fidell LS. Using multivariate statistics. 6th ed. London (UK): Pearson; 2013.

40. Jacob J, De Guzman RG. Effectiveness of taking in the good based-bibliotherapy intervention program among depressed Filipino female adolescents. Asian $\mathcal{F}$ Psychiatry 2016;23:99-107.

41. Zhou H, Hao N, Du Y, et al. Validity and reliability of the Chinese version of the Kutcher Adolescent Depression Scale. Chin Ment Health 7 2015;29:413-8.

Affiliations: Departments of Community Health and Psychiatry (Lowe, Gibson) and of Sociology, Psychology and Social Work (Lipps) and School of Education (Jules), The University of the West Indies - Mona, Kingston, Jamaica; Department of Psychiatry (Kutcher), Dalhousie University, Halifax, NS

Contributors: Garth Lipps and Gillian Lowe contributed to the conception of the project, designed the project, collected the data in Jamaica, analyzed and interpreted the data, and contributed to the drafting of the manuscript. Roger Gibson and Mia Jules contributed to the design of the project, interpretation of the data and drafting of the manuscript. Stanley Kutcher contributed to the conception of the project and critically revised the manuscript for important intellectual content. Mia Jules collected the data in Barbados. All of the authors gave final approval of the version to be published and agreed to be accountable for all aspects of the work.

Funding: This work was supported by New Initiatives grant 15112P, Principal's Office, The University of the West Indies.

Supplemental information: For reviewer comments and the original submission of this manuscript, please see www.cmajopen.ca/content/6/3/ E248/suppl/DC1. 